\title{
Modeling a Low-temperature Compressed Air Energy Storage with Modelica
}

\author{
Marcus Budt ${ }^{1}$, Daniel Wolf ${ }^{1}$, Roland Span ${ }^{2}$ \\ ${ }^{1}$ Fraunhofer Institute for Environmental, Safety, and Energy Technology UMSICHT \\ Osterfelder Straße 3, 46047 Oberhausen, Germany \\ marcus.budt@umsicht.fraunhofer.de, daniel.wolf@umsicht.fraunhofer.de \\ ${ }^{2}$ Ruhr-University Bochum, Faculty for Mechanical Engineering \\ Universitätsstraße 150, 44780 Bochum, Germany \\ roland.span@thermo.rub.de
}

\begin{abstract}
The paper deals with the simulation of an innovative adiabatic compressed air energy storage plant. These plants are able to store electrical energy by compressing and expanding ambient air. In contrast to other approaches the plant layout examined in this paper works with much lower storage temperatures of just $100-200{ }^{\circ} \mathrm{C}$. Aim of the modeling effort is to dynamically simulate the plant and to analyze the thermodynamics of the system. Here, off-design behavior regarding turbomachinery output temperatures, pressure losses and heat flows are of particular interest.
\end{abstract}

Keywords: compressed air; energy storage; thermal storage; low-temperature; CAES; modeling; Modelica

\section{Introduction}

The increasing share of renewable power generation, particularly of fluctuating wind and solar generation, leads to a time-based shift between supply and demand. A result of this development is the increasing demand for energy storage. Beside short time storage technologies like batteries or flywheels, a significant demand for bulk storage like pumped hydro energy storages (PHES) arises. For Europe the future PHES potential is rather limited due to siting restrictions including proper topological conditions. One alternative is compressed air energy storage (CAES), which provides energy capacities and power ranges comparable to those of PHES. This renders CAES a promising option for bulk electricity storage in the near term future.

\section{Compressed Air Energy Storage}

The idea of using compressed air to store energy is rather old. Beside pressurized air driven vehicles for special applications, there are two so called diabatic CAES plants, which are already in operation. The first CAES in Huntorf (Germany) works since 1978. The second one, located in McIntosh (USA), is in service since 1991. The concept of CAES is to absorb electricity by compressing ambient air by an electrically driven compressor in times of surplus electricity in the grid. The compressed air can be stored in a pressurized containment of any kind. The mentioned CAES plants use solution mined underground salt caverns as compressed air storage (CAS). Because of the surrounding salt these caverns are technically tight without additional sealing. During discharge the compressed air is released from the CAS and heated up to drive an expansion turbine. The expansion turbine is connected to a generator supplying electric power to the grid.

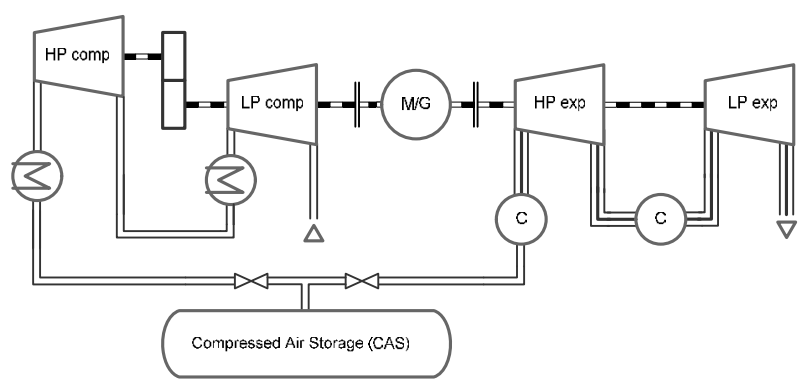

Figure 1: Block diagram of the first compressed air energy storage plant located in Huntorf, Germany [1]

As shown on the left hand side of Figure 1 the whole amount of heat generated during compression is cooled to the ambient in today's diabatic CAES. Therefore, two main intercoolers are installed in the Huntorf plant, the first one between the low and high 
pressure compressor units and the second one between high pressure compressor unit and CAS. The second intercooler ensures that the air enters the $\mathrm{CAS}$ at a maximum temperature of $35^{\circ} \mathrm{C}$, because higher temperatures would destabilize it. In expansion mode these plants use a gas fired combustion chamber to pre-heat the compressed air before the expansion in order to protect the turbine and to increase the power output. In the Huntorf plant this pre-heating again is located at two points of the process. First, the air is pre-heated before entering the pressure expander and then again between the two expander units. Therefore, both diabatic CAES plants are, in the proper meaning of the word, no pure energy storages. They are rather a type of hybrid gas plants.

\subsection{Current adiabatic design approaches}

Nowadays CAES approaches aim on cycle operation without the need of fossil fuels to heat up the compressed air during expansion. Therefore, a thermal energy storage (TES) is applied. It captures the heat of compression during the charging process and allows for using it to heat up the air in the discharging process. Figure 2 shows the block diagram of an adiabatic compressed air energy storage (A-CAES).

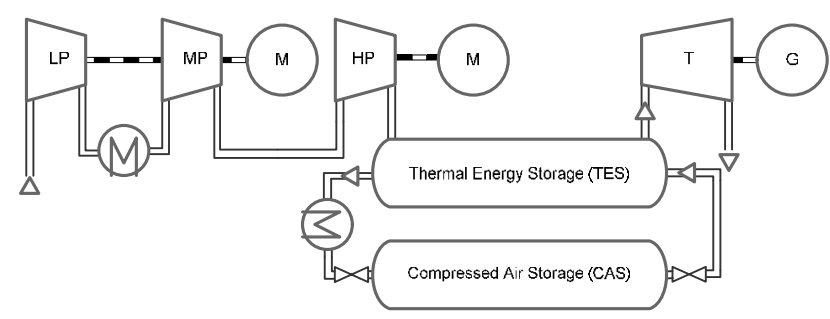

Figure 2: Concept of an adiabatic compressed air energy storage
Advantages of the concept are the high cycle efficiency of up to $70 \%$ and the high energy density of the TES [2]. The main challenges are the demand for a compressor redesign to face temperatures of up to $650{ }^{\circ} \mathrm{C}$ and the development of a large packed bed TES, which can withstand high temperatures and pressures of around 70 bar simultaneously.

\subsection{Low-temperature concept}

To avoid the previously mentioned challenges Fraunhofer UMSICHT investigates the possibility to design A-CAES plants for lower TES temperatures. Interesting results for a two-stage A-CAES at $350{ }^{\circ} \mathrm{C}$ [1] and the fact that the cycle efficiency of A-CAES is not governed by the Carnot efficiency led to the current $100-200{ }^{\circ} \mathrm{C}$ LTA-CAES concept [3].

Figure 3 shows the plant layout of a LTA-CAES. Due to the use of an eight stage radial inflow compressor it is possible to cool the compressed air after each stage. This leads to a reduction of compression work and a limitation of the TES temperature to $100-200{ }^{\circ} \mathrm{C}$. The chosen temperature depends on the economic optimum between increasing revenue through better cycle efficiencies on the one hand and increasing investment costs for the TES due to higher temperatures on the other hand. In the addressed temperature range a pumpable TES medium like pressurized water or thermal oil can be used. Independent of the TES temperature there is always a part of compression heat, which cannot be reused during the discharging process. In the shown stand-alone plant version (Fig. 3) this heat is cooled to ambient air temperature by additional intercoolers. The stored heat is used to pre-heat the compressed air before entering each expander stage. This results in cycle efficiencies of up to $67 \%$.

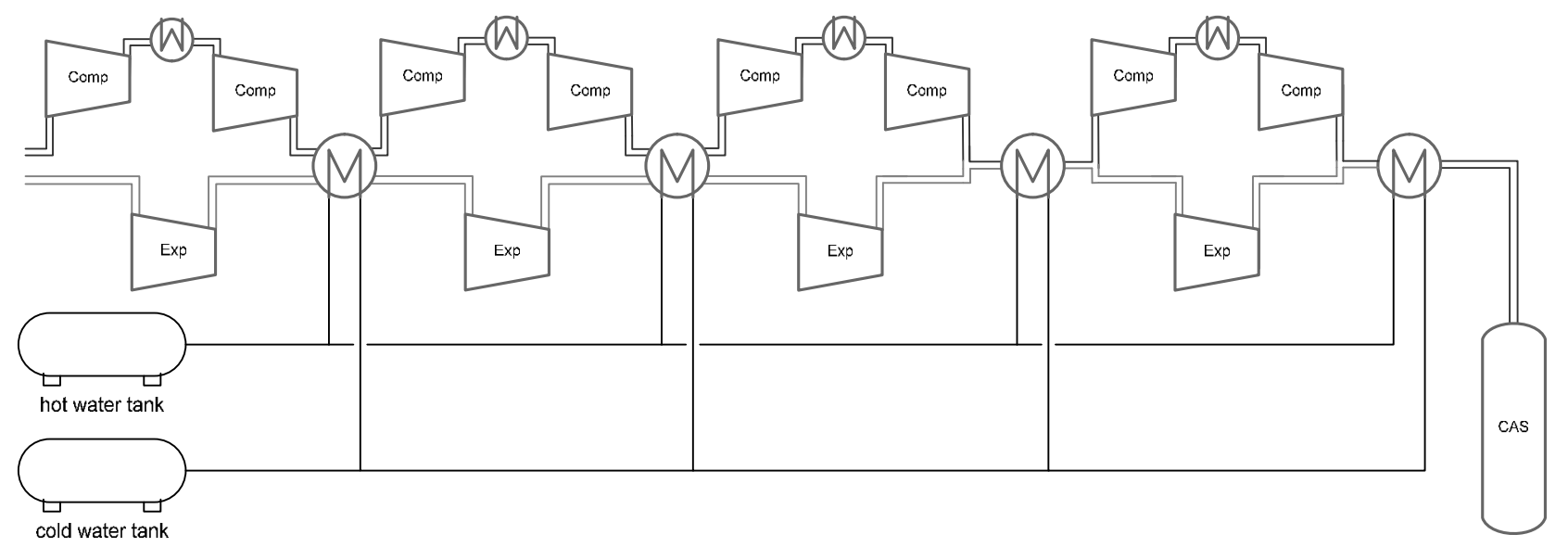

Figure 3: Low-temperature adiabatic compressed air energy storage concept 


\section{Current plant model}

In the ongoing development process the model described below enables the examination of the thermodynamic behavior of the plant especially in offdesign operation. The current plant model is based on Modelica 3.2 standard libraries, especially on the Modelica.Fluid library by Casella et al. [4], and implemented in Dymola 2012 FD01 [5]. The compressed air is currently assumed as an ideal gas mixture of dry air, taken from the Modelica.Media package 'DryAirNasa'.

Table 1: Symbol table

\begin{tabular}{|c|c|c|}
\hline symbol & meaning & unit \\
\hline $\mathrm{p}$ & pressure & $\mathrm{Pa}$ \\
$\mathrm{h}$ & enthalpy & $\mathrm{J} / \mathrm{kg}$ \\
$\mathrm{T}$ & temperature & $\mathrm{K}$ \\
$\mathrm{X}$ & mass fraction & - \\
$\mathcal{Q}$ & heat flow & $\mathrm{W}$ \\
$\mathrm{I} \boldsymbol{\alpha}$ & mass flow & $\mathrm{kg} / \mathrm{s}$ \\
$\mathrm{y}$ & specific useful flow work & $\mathrm{J} / \mathrm{kg}$ \\
$\kappa$ & isentropic exponent & - \\
$\mathrm{R}$ & gas constant & $\mathrm{J} / \mathrm{kg} \mathrm{K}$ \\
$\prod$ & compression/expansion ratio & - \\
$\eta$ & efficiency & - \\
$\mathrm{P}$ & power & $\mathrm{W}$ \\
\hline
\end{tabular}

\subsection{Standard library components}

As intended by using Modelica to simulate the LTA-CAES, many standard library components could be used in the model. Among sensors, PIDcontrollers, valves and Fluid.Sources, the whole turbomachinery piping is implemented by Modelica.Fluid pipe models. The CAS is assumed as a solution mined underground salt cavern and is based on the 'ClosedVolume' Modelica.Fluid model.

\subsection{Heat exchanger modeling}

In a first step the used heat exchanger models are simplified to heat sinks and sources without any mass or energy storage capacities. The current approach also assumes an ideally regulated water mass flow through the heat exchanger components.

The pressure loss of the heat exchanger is a fixed value given by the user. The output pressure is calcu- lated according to Equation 1 if the current mass flow exceeds a given minimum. Otherwise the pressure loss is set to zero. The resulting step is smoothed by a first order transfer function.

$$
p_{\text {out }}=p_{\text {in }}-\Delta p
$$

Another fixed input value is the outlet temperature ( $\left.\mathrm{T}_{\text {out }}\right)$, which is assigned to the air leaving the heat exchangers in times of required heat transfer. Therefore, the enthalpy at the outlet is calculated using this given temperature (Eq. 2).

$$
h_{\text {out }}=h\left(p_{\text {out }}, T_{\text {out }}, X_{i, \text { in }}\right)
$$

The required heat flow to reach this temperature is calculated by the energy balance equation (Eq. 3) and given to the user as an output value.

$$
0=\dot{Q}_{i}+\dot{m}_{i n} \cdot h_{i n}+\dot{m}_{\text {out }} \cdot h_{\text {out }} \quad \text { Eq.3 }
$$

\subsection{Turbomachinery modeling}

The main components of the LTA-CAES plant are the compressor and expander turbomachineries. Particular attention was paid to these components during model development. The LTA-CAES concept includes an eight stage compressor and a four stage expander, both integrally geared. In the model each of the turbomachinery stages is characterized by two characteristic diagrams, one with regard to the pressure ratio and the other with regard to the polytropic stage efficiency. In the LTA-CAES concept developed so far, both compressor and turbine are supposed to run on fixed speeds.

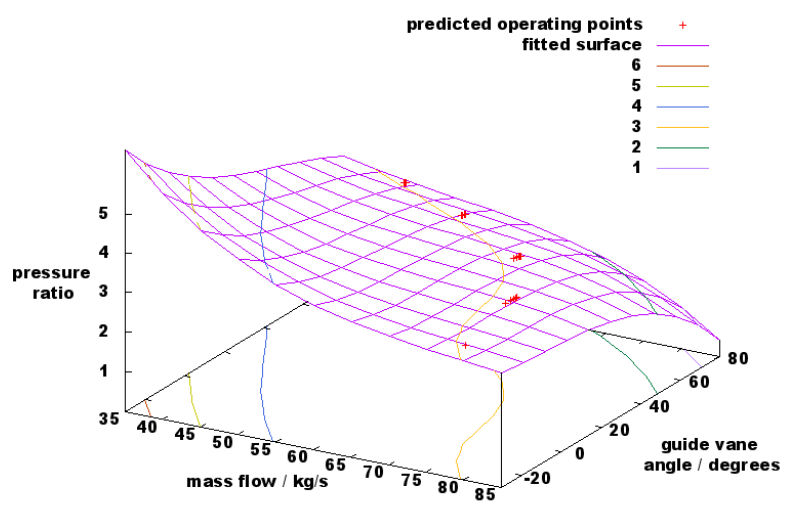

Figure 4: First stage compression ratio diagram

In the LTA-CAES concept the control of the operational point is carried out by variable guide vanes. 
Their impact on turbomachinery operation is determined by the current angle of the guide vanes. Figure 4 shows the pressure ratio for the first compressor stage as a function of air mass flow and guide vane angle.

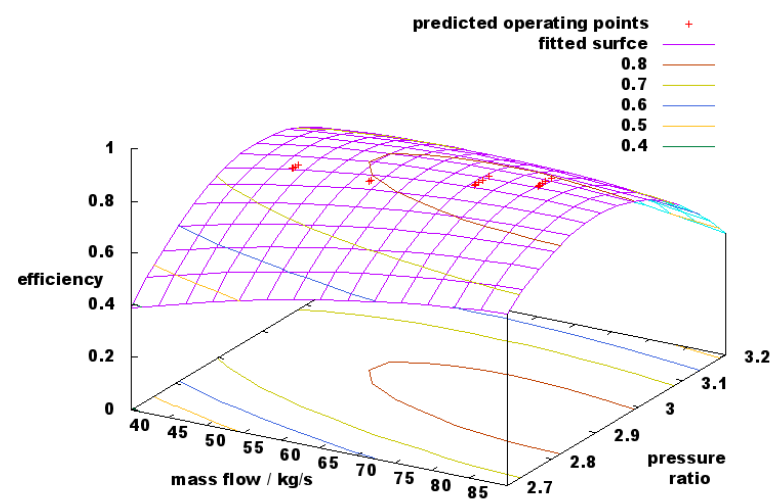

Figure 5: First stage polytropic efficiency diagram

The polytropic efficiency of the same compressor stage is a function of air mass flow and pressure ratio as depicted in Figure 5.

All these diagrams are based on predicted values for operating and off-design points. The parameters of the second (efficiency) and third (compression/expansion ratio) order surface functions are fitted by the open source software GnuPlot in order to reproduce the available off-design point behavior.

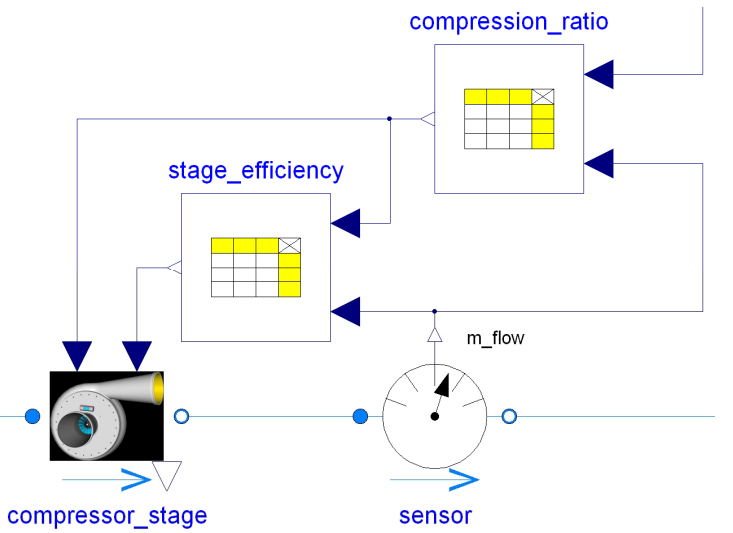

Figure 6: Compressor stage model with inputs from characteristic diagrams

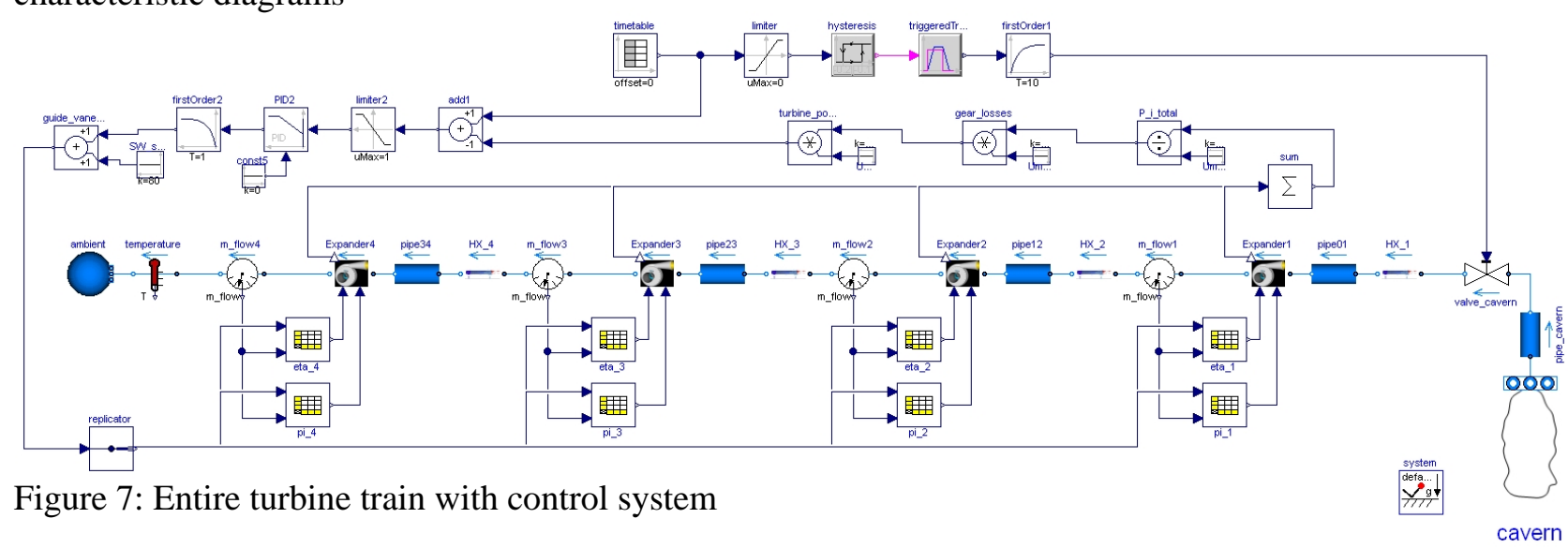

As shown in Figure 6 the characteristic diagrams are implemented as a 'CombiTable2d' in Modelica.

With the current mass flow delivered by a sensor and the guide vane angle given by the control instance as inputs, these tables deliver their values as inputs for the Modelica.Fluid based compressor stage model. The model uses these values to calculate the change in enthalpy. Therefore, the isentropic exponent $\kappa$ is calculated at suction conditions by the used Modelica.Media model. Together with the stage inlet temperature $\left(T_{\text {in }}\right)$ and the compression ratio input value ( $\left.\prod_{\text {in }}\right)$, Equation 4 is used to calculate the specific isentropic useful flow work $\left(\mathrm{y}_{\mathrm{s}}\right)$ assuming ideal gas behavior.

$y_{s}=\left(\frac{\kappa}{\kappa-1}\right) \cdot R \cdot T_{i n} \cdot\left[\Pi_{i n}^{\frac{\kappa-1}{\kappa_{i}}}-1\right] \mathrm{Eq} .4$

Equation 5 shows the conversion of the polytropic efficiency input value $\left(\eta_{\mathrm{pol}, \text { in }}\right)$ to isentropic efficiency $\left(\eta_{\mathrm{s}}\right)$.

$$
\eta_{s}=\frac{\Pi_{i n}^{\frac{\kappa-1}{\kappa}}-1}{\Pi_{i n}^{\frac{\kappa-1}{\kappa} \frac{1}{\eta_{p o l}, i n}}-1}
$$

The division by the isentropic efficiency $\left(\eta_{\mathrm{s}}\right)$ results in the effective change in enthalpy $(\Delta \mathrm{h})($ Eq. 6$)$.

$$
\Delta h=\frac{y_{s}}{\eta_{s}}
$$

The output pressure is calculated by Equation 7 .

$$
p_{\text {out }}=p_{i n} \cdot \Pi_{\text {in }}
$$


With the given pressure and enthalpy at the output port of the compressor stage model, Modelica.Media is able to calculate values like the output temperature.

To match the energy balance (Eq. 8) there is an additional model output value called internal consumed power $\left(\mathrm{P}_{\mathrm{i}}\right)$.

$$
0=P_{i}+\dot{m}_{i n} \cdot h_{i n}+\dot{m}_{\text {out }} \cdot h_{\text {out }}
$$

Since there is no change in air mass flow within the stage, the mass balance shown in Equation 9 is valid.

$$
0=\dot{m}_{i n}+\dot{m}_{o u t}
$$

In the turbine model both characteristic diagrams are generated as functions of mass flow and guide vane angle from literature data (Fig. 7) [6, 7]. Apart from that, the same kind of input values and a corresponding set of equations are used. It is therefore not described in detail in this paper.

Simulations of multi-stage turbomachineries are very complex since a pressure or temperature change in one stage has a direct influence on the following ones. This especially applies for off-design conditions and for interim cooling or heating processes. The fundamental advantage of modeling each compressor or turbine stage as an independent model is the ability to calculate their interactions without complex methods like the principle of superposition for the compressor or the law of cone for the turbine.

\subsection{Control system}

Since the plant model is not intended to simulate start-up and shut-down phase in detail, the modeling of the surge control valve was omitted. The start-up and shut-down of the plant is therefore simplified. Once started, the consumed or produced power is adjusted by a PID-controller system. The values the control system should maintain are given to the model by a Modelica 'timeTable' connected to an external file. Programming both stage types in the shown pressure driven way leads to a turbomachinery system with a self-regulating mass flow rate. The control system is able to change the guide vane angle and therefore the operating point of the plant. As proven by comparison, the model behavior and the guide vane angle control simulate the real performance with sufficient accuracy.

\section{First results}

The presented simulation results refer to a model parameterization of a plant with an eight stage $53 \mathrm{MW}$ compressor unit and a four stage expander unit with an output power of $30 \mathrm{MW}$. The TES temperature is limited to $150{ }^{\circ} \mathrm{C}$ and the cavern pressure varies in the range between 100 and 152 bar assuming a cavern depth of $1500 \mathrm{~m}$. The chosen high pressure leads to a high energy density in the cavern. The required geometrical volume of the cavern is $30,000 \mathrm{~m}^{3}$. With this cavern the LTA-CAES plant is able to operate six full load hours of charging as well as discharging.

\subsection{Plant operation}

Like normal power plants, usual diabatic CAES plants preferably work only in their full load operating point, where optimal efficiency can be reached. Therefore, the first simulation results show the plant behavior at design point, which reflects a full cycle of charging and discharging the cavern at maximum power.

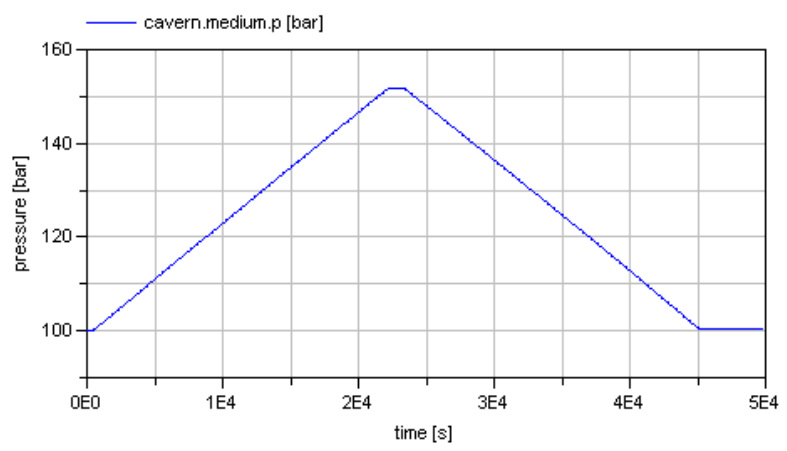

Figure 8: Cavern pressure during full cycle process

Figure 8 shows the cavern pressure increasing from 100 to 152 bar and then decreasing to 100 bar again during a full charge and discharge period of 6 hours $(21,600 \mathrm{~s})$ each.

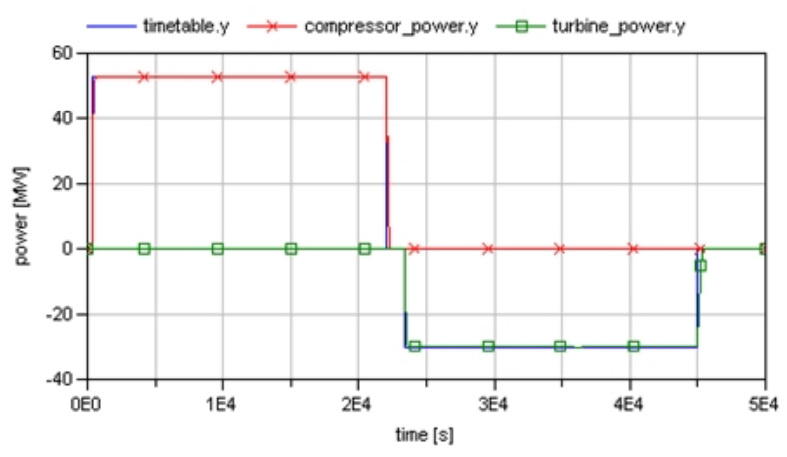

Figure 9: Timetable signal and corresponding compressor power consumption and turbine power output 
During the charging process $(400-22,000 \mathrm{~s})$ the requested power consumption is set to $53 \mathrm{MW}$. While discharging the LTA-CAES the requested power output is set to the maximum output power of $30 \mathrm{MW}$. This call starts at 23,400 s and continues to 45,000 s. As shown in Figure 9 the timetable provides the corresponding values to the model and the compressor and turbine power follows this demand.

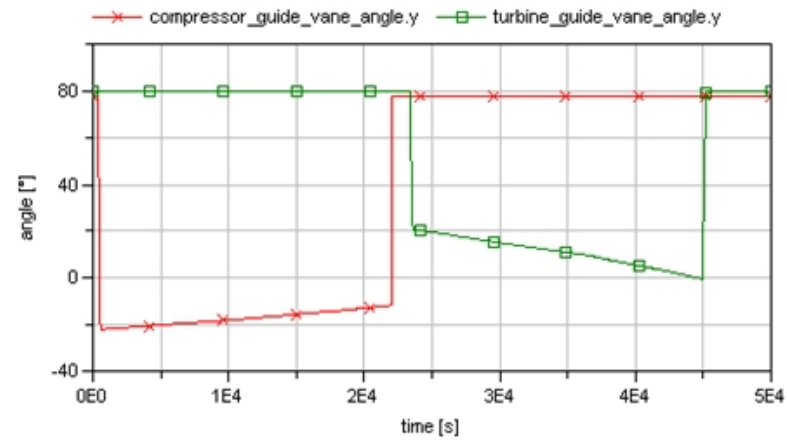

Figure 10: Guide vane angle adjustment

Figure 10 shows the guide vane angle in the same time period, regulated by the control system to match the timetable power signal. It can be seen, that the compressor guide vanes are continuously closing to hold the power consumption of $53 \mathrm{MW}$ during the charging process. In contrast the turbine guide vanes are opened up more and more during the discharge process in order to provide a constant power output of $30 \mathrm{MW}$. The corresponding change in air mass flow due to the guide vane adjustment is shown in Figure 11.

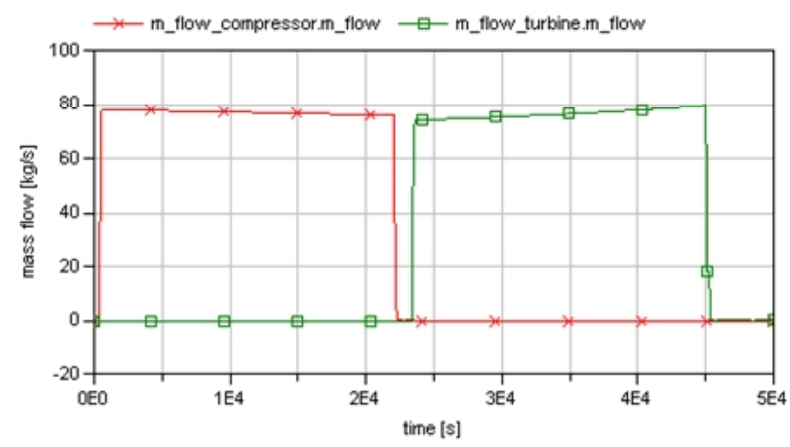

Figure 11: Mass flow through compressor and turbine train

\subsection{Compressor train}

One aspect of the previously mentioned complex interactions between each of the compressor stages can be observed in Figure 12. It can be seen that the increasing cavern pressure is not reached by a slightly increasing compression ratio in each stage. Rather there is a strong increase of the compression ratio in the higher stages and nearly no change in the first three stages.

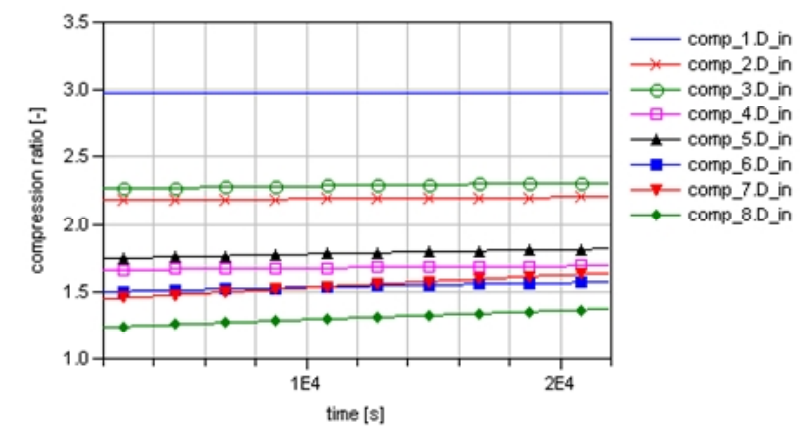

Figure 12: Compressor stages compression ratios

As a result of this compressor behavior the power consumed by the stages does not behave similar (Fig. 13). Especially, the first and the last compressor stage show an opposed development. While all the other stages consume a constant power, due to the reduction of mass flow (Fig. 11) by guide vane adjustment, the last stage consumes more and more power. In this compressor stage the strong increase in compression ratio overcompensates the reduced mass flow. In contrast the power of the first stage decreases.

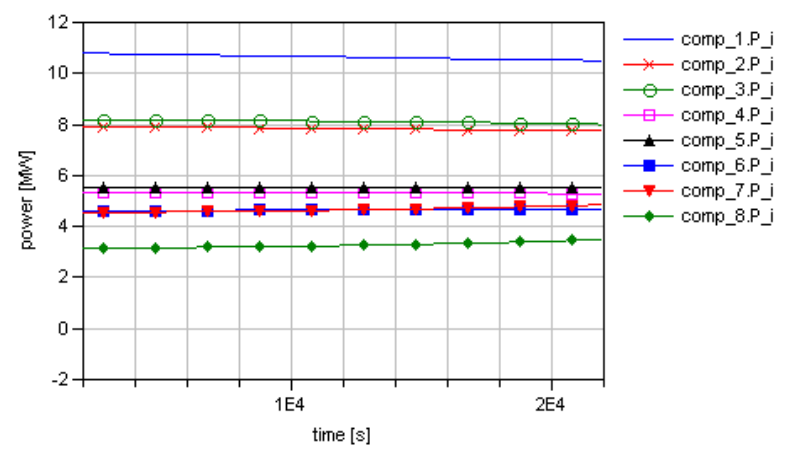

Figure 13: Compressor stages power consumptions

According to the different change of compression ratio and power consumption in all of the stages, the efficiency course also varies between each of them. Depending on that the temperature of the air entering the heat exchangers varies during the charging process. Figure 14 shows the heat flow rates each of the heat exchangers has to provide. The previously described behavior of the stages can be seen here again clearly. The wide range of heat flow rates arises from the different tasks of the heat exchangers. The heat exchangers two, four, six and eight are designed to deliver a preferably constant heat flow to the TES. The others just cool the process air down to a defined temperature to ensure the maximum TES temperature of $150{ }^{\circ} \mathrm{C}$ in this plant layout. Therefore, their 
heat flows vary according to the compression ratio of the previous compressor stage.

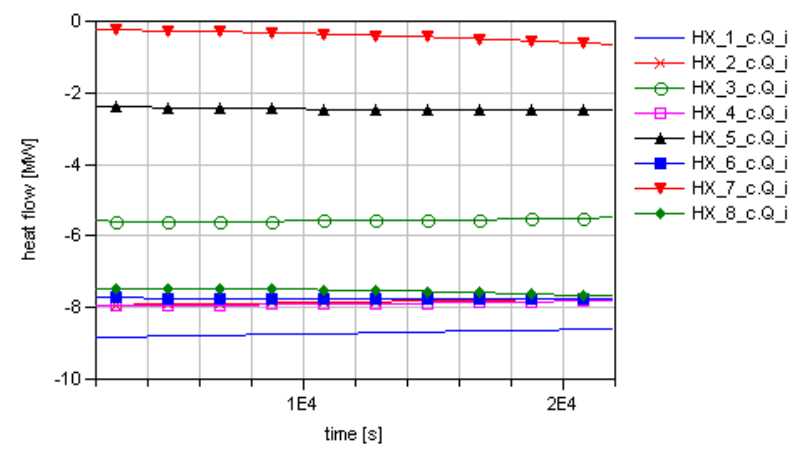

Figure 14: Heat flow rates of the heat exchangers during the compression process

\subsection{Turbine train}

By opening the turbine guide vanes (Fig. 10) the control system increases the air mass flow (Fig. 11) to compensate the decrease in turbine output power due to the decrease in cavern pressure. Despite the considerable decrease of turbine inlet pressure of 52 bar during discharging, the turbine mass flow increases only by $5.4 \mathrm{~kg} / \mathrm{s}$, enough to allow for a constant power output. The corresponding dynamic behavior of each of the four expander stages is shown in the Figures 15 and 16.

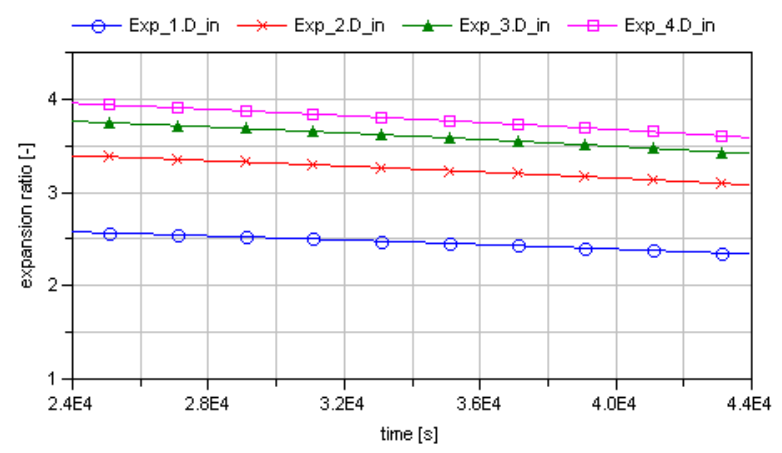

Figure 15: Expander stages expansion ratios

Corresponding to the decreasing cavern pressure depicted in Figure 8, the expansion ratio of each stage decreases as well. It can be seen, that each stage has an individual course (Fig. 15). These pressure driven expansion ratios, together with the adjustable guide vane angle, define the mass flow through the expander stages as depicted in Figure 11.

Depending on the self-adjusting mass flow and the guide vane angle given by the control system, each stage has an individual efficiency course during discharging.

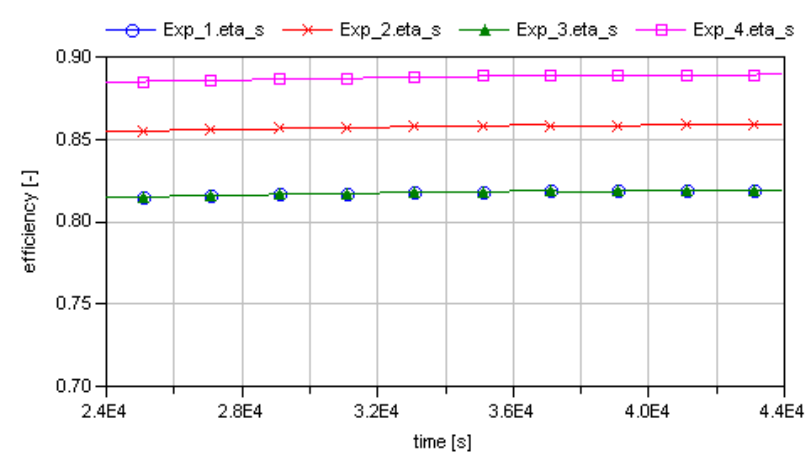

Figure 16: Turbine stages isentropic efficiencies

Figure 16 shows the efficiencies of the four expander stages during the discharging process. The values seem to be constant. In fact there is a minimal rise at the beginning of the discharging process followed by a slightly decrease towards the end. The maximum value can be found at the point the guide vane angle (Fig. 10) crosses the zero degree position, because at this condition the expander stages reach their optimal operating point. The nearly constant efficiency over the whole discharging process demonstrates the general advantage of turbomachinery control by guide vane adjustment.

As a result of the changing expansion ratios and efficiencies the output temperatures of the expander stages vary, too. Because of the small change in efficiencies, the expansion ratios are the main influential variables. Together with the air mass flow these temperatures govern the heat exchanger requirements. Figure 17 shows air temperatures at the inlet of each heat exchanger. Since the assumed slow discharge of the cavern has a negligible effect on the cavern temperature, the air temperature at the first heat exchanger inlet is constantly set to $50{ }^{\circ} \mathrm{C}$. The inlet temperatures for the other heat exchangers are equal to the previous turbine stages output temperatures. As to be expected, increasing temperatures depending on the decreasing expansion ratios of the turbine stages can be observed.

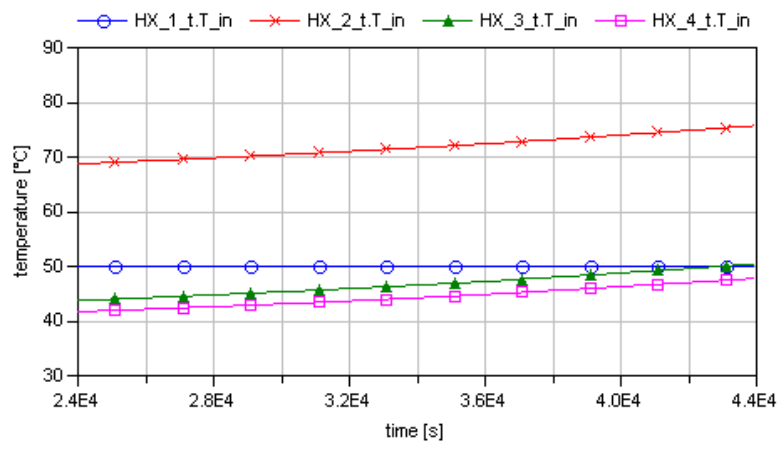

Figure 17: Temperature of the heat exchanger inflowing air 


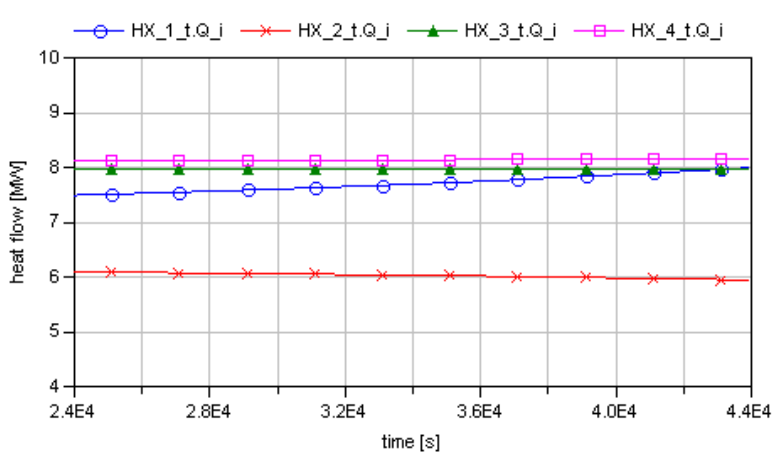

Figure 18: Heat flow rates into the heat exchangers needed to heat up the airflow to $150{ }^{\circ} \mathrm{C}$

The heat flow rates of the heat exchangers to heat up the air to $150{ }^{\circ} \mathrm{C}$ show an interesting behavior (Fig. 18). The heat flow rate required by the first heat exchanger is increasing due to the rising mass flow. In contrast the accordingly expected heat flow increase at the other stages is compensated by the higher input temperatures and the consequently smaller temperature difference between inlet and outlet air stream.

\subsection{Model performance}

The shown results were generated using Dymola 2012 FD01 on a $3 \mathrm{GHz}$ dual-core system with $4 \mathrm{~GB}$ of RAM. The model was initialized with initial guess values from stationary calculations. Apart from some difficulties at points of sudden step responses, which could be solved by smoothing these, the model works very fine. The model performs robust and quick, mainly due to neglecting mass and energy storage in compressor and expander stages as well as in the heat exchangers implemented so far. The simulation of the whole 50,000 s charging and discharging cycle (Dassl 0.0001; 500 output intervals) requires $9 \mathrm{~s}$. Leveling up the number of output intervals to 5,000 increases the simulation time to $13.7 \mathrm{~s}$.

\section{Conclusions and work in progress}

The basic results of the model show the potential of using dynamic simulation to investigate the thermodynamic behavior of an A-CAES. Especially, the complex interactions between turbomachinery stages, heat exchangers and pressure losses can be analyzed in detail. Furthermore, the model allows the analysis of off-design behavior, which is getting more and more important in today's electricity markets. The influence of off-design operation on the overall cycle efficiency can be evaluated as well.
Besides the presented results work further progresses. The presented model will be extended by:

- the implementation of detailed heat exchanger models

- the implementation of external media libraries for humid air to investigate the influence of condensing water in the process

- the implementation of alternative turbomachinery concepts

In the absence of experimental data the compressor model so far had to be validated by data from steadystate calculations in different working points. Here, the model results match the steady-state ones very well. A detailed off-design validation by experimental data for the turbomachinery is aimed at for the future.

The final goal of the research work will be an iterative process by using both, the presented dynamic simulation model and the economic optimization model GOMES ${ }^{\circledR}$ [8]. This way an optimization of technical and economical aspects for a given business case will be possible.

\section{Acknowledgements}

The authors thank the German Federal Ministry for the Environment, Nature Conservation and Nuclear Safety for funding the project »Adiabates Niedertemperaturdruckluftspeicherkraftwerk zur Unterstützung der Netzintegration von Windenergie« (FKZ 0325211).

\section{References}

[1] Wolf D.: Methods for Design and Application of Adiabatic Compressed Air Energy Storage Based on Dynamic Modeling. Bochum, Germany: PhD thesis, RuhrUniversität Bochum, 2010, UMSICHTSchriftenreihe 65, urn:nbn:de:0011-n1546519, 2011.

[2] Marquardt R., Hoffmann S., Pazzi S., Klafki M., Zunft S.: AA-CAES - Opportunities and challenges of advanced adiabatic compressed air energy storage technology as a balancing tool in interconnected grids. In: 40. Kraftwerkstechnisches Kolloquium 2008, Vol. 2, Technische Universität Dresden (Ed.), 2008. 
[3] Budt M., Wolf D., Prümper H.-J.: A Low-temperature approach to Adiabatic Compressed Air Energy Storage. Proceedings of $12^{\text {th }}$ International Conference on Energy Storage - INNOSTOCK, Lleida, Spain, 2012.

[4] Casella F., Otter M., Proelss K., Richter Ch., Tummescheit H.: The Modelica Fluid and Media library for modeling of incompressible and compressible thermo-fluid pipe networks. Proceedings of $5^{\text {th }}$ International Modelica Conference, Vienna, Austria, 2006.

[5] Dassault Systèmes, Dymola 2012 FD01.

[6] Moustapha H., Zelesky M.F., Baines N.C., Japikse D.: Axial and Radial Turbines. Concepts NREC (Ed.), 2003.

[7] Bloch H., Soares C.: Turboexpanders and process application. ButterworthHeinemann (Ed.), 2001.

[8] Wolf D., Kanngießer A., Budt M., Dötsch Ch.: Adiabatic Compressed Air Energy Storage co-located with wind energy multifunctional storage commitment optimization for the German market using GOMES. In: Energy Systems, Vol. 3, Issue $2,2012$. 
